\title{
Iconografia, História e Antigüidade Grega I: tendências gerais*
}

\author{
Marcelo Rede \\ IFCH/Universidade Federal Fluminense
}

TEXTE \& IMAGE. Actes du Colloque International de Chantilly (13-15 de ou1984 tubro de 1982). Paris, Les Belles Lettres.

F. LISSARRAGUE \& F.THELAMON (eds.) - IMAGE ET CÉRAMIQUE GRECQUE. 1983 Actes du Colloque de Rouen (25-26 de novembro de 1982). Rouen, Publications de l'Université de Rouen, n. 96.

C.BÉRARD, C.BRON \& A.POMARI (eds.) - IMAGES ET SOCIÉTÉ EN GRÈCE 1987

ANCIENNE. L'ICONOGRAPHIE COMME MÉTHODE D'ANALYSE. Actes du Colloque International de Lausanne (811 de fevereiro de 1984). (Cahiers d'Archéologie Romande, 36) Lausanne.

C.BRON \& E.KASSAPOGLOU (eds.) - L'IMAGE EN JEU. DE L'ANTIQUITÉ À 1992

PAUL KLEE. Yens-sur-Morges, Institut d'Archéologie et d'Histoire Ancienne de l'Université de Lausanne/Éditions Cabédita.

Nas últimas décadas, tem-se acentuado a atenção dos estudiosos para com o uso da imagem como fonte da construção do conhecimento histórico. Não seriam poucos os antecedentes, mas a dimensão do movimento é inédita: a institucionalização e a generalização das preocupações teóricometodológicas acerca da relação da História com a iconografia assumiram um caráter constante e profundo ${ }^{1}$. Os esforços no sentido de pensar a imagem no
* A realização deste ensaio bibliográfico foi-me sugerida pelo Prof. Ulpiano Bezerra de Meneses, da Universidade de São Paulo, no interior das atividades de seu curso de Pós-Graduação sobre fontes iconográficas e o trabalho histórico, ministrado no Museu Paulista, durante o 20 . semestre de 1991. Agradeço seu incentivo e sua colaboração.

1. Apenas para citar um exemplo bastante conheci- 
do entre nós, em 1976, um encontro de especialistas de diversas áreas, sob a coordenação de M.Vovelle, reflete o quadro de uma necessidade de reflexão sobre as técnicas, os métodos, os conceitos e as teorias implicados no trabalho com a imagem no campo da história das mentalidades. Os resultados do encontro serão publicados, mais tarde, sob o título Iconograpbie et Histoire des Mentalités . Paris, CNRS, 1979. Para uma visão geral deste quadro de preocupações no interior da historiografia ver: C.F. Cardoso, 1990. interior das práticas historiográficas estendem-se, hoje, aos diversos setores cronológicos da história. Entretanto, deve-se lembrar que, no que diz respeito aos estudos da Antigüidade Clássica, a imagem sempre ocupou um lugar de destaque, desde a configuração de uma atividade sistemática de pesquisa sobre a história greco-romana, no século XVIII. Uma tonga tradição, por assim dizer, alicerçou as formas de relação com a imagem no trabalho do historiador e foi responsável pela criação de uma consciência impar em termos de levantamento e organização do material imagético clássico. Foram justamente estes dois procedimentos que nortearam todo um trabalho de identificação, seleção e classificação que caracterizou importantes empreendimentos no decorrer deste século, como o Corpus Vasorum Antiquorum, as publicações de J.D.Beazley, J.Boardman e, mais recentemente, o monumental Lexicon Iconographicum Mythologiae Classicae, em curso de publicação desde 1981.

Paralelamente ao esforço de organização do material iconográfico, desenvolveram-se algumas posturas do historiador da Antigüidade Clássica face à imagem, que implicaram formas variadas de seu uso na produção do discurso histórico. A inserção da imagem em seu horizonte de preocupações, colocou, desde logo, ao historiador a necessidade de refletir sobre os pressupostos teóricos e os instrumentos metodológicos inerentes ao tratamento de uma fonte com particularidades tão evidentes. Aos trabalhos que utilizavam efetivamente a imagem para fazer história somou-se, assim, uma vasta bibliografia que se propunha pensar as questões pertinentes às relações entre o historiador e a imagem. $O$ conjunto destas reflexões é, hoje, enorme e variado, não sendo poucos os debates em seu interior. Um balanço global das diversas contribuições seria desejável, mas excede às intenções deste artigo. De modo mais delimitado, procurarei examinar, aqui, um conjunto de trabalhos que formam um bloco razoavelmente coerente, embora não monolítico, de contribuiçōes teóricometodológicas para o estudo da imagem e da história na Grécia Antiga.

A partir de finais da década de setenta, verifica-se um grande esforço de problematização da questão iconográfica entre os estudiosos da sociedade grega e helenistas em geral. A freqüência com que se realizam encontros e colóquios e, conseqüentemente, o número de publicações coletivas são representativos das indagações e buscas de respostas advindas de uma nova forma de relacionamento entre a história e a iconografia. São algumas dessas publicações - escolhidas pela sua representatividade, por definirem uma linha de pesquisa mais ou menos homogênea e por terem uma explícita orientação de caráter teórico e metodológico - que serão objeto deste balanço crítico. Notar-se-á, imediatamente, uma concentração em um grupo de publicações e autores franco-suíços. É uma decorrência do corte estabelecido: os trabalhos, e a linha de pesquisa por eles definida, são um produto da cooperação de historiadores do eixo Paris-Lausanne, sediados particularmente no Centre de recherches comparées sur les sociétés anciennes, de Paris, e no Institut d'archéologie et d'histoire ancienne, da Universidade de Lausanne. Assim, serão considerados os Colóquios de Chantilly (1982, publicado em 1984), de Rouen 11982, publicado em 1983), e de Lausanne (1984, publicado em 1987), além de uma publicação coletiva do referido Instituto de Arqueologia 
(de 1992). A seleção necessariamente efełuada não deve fazer esquecer publicações contemporâneas, que foram excluídas apenas por não corresponderem aos critérios de escolha ditados pelo interesse em explicitar uma das abordagens predominantes no estudo da iconografia grega ${ }^{2}$.

Trata-se, aqui, de realizar um balanço das contribuições apresentadas e tentar iniciar um mapeamento das idéias e práticas que caracterizam esse momento de inserção diferenciada da imagem no horizonte da história da Grécia Antiga. Inserção que possui suas peculiaridades, que define todo um reenquadramento das questões colocadas ao historiador e que confere uma dimensão nova às suas respostas. Para o quê e como são utilizadas as imagens? Quais são os procedimentos metodológicos propostos para sua decifração? Qual sua posição frente aos demais produtos históricos e, conseqüentemente, como tratála em relação aos outros documentos? Quais são os pressupostos teóricos que lastreiam o trabalho com imagens? Em resumo, tratase de identificar e caracterizar as tendências (em especial a majoritária) da análise historiográfica e de examinar criticamente como os seus procedimentos e resultados comportam-se em relação à produção do conhecimento histórico.

Fragmentação e tendências: o "Grupo Semiológico"

Duas observações preliminares fazem-se necessárias. Em primeiro lugar, não existe uma homogeneidade absoluta entre os procedimentos teóricos e metodológicos das dezenas de contribuições aqui examinadas. Já na apresentação do Colóquio de Lausanne, C.Bérard (1987:7) identificava a presença de duas abordagens complementares e não opostas, que se aglutinavam em torno dos dois centros de pesquisa já citados, Paris e Lausanne. De fato, nem só essas tendências estão presentes. Poder-se-ia identificar, por exemplo, uma massa de artigos, menos teóricos e conceituais, cuja marca principal é um certo empirismo que reduz o trabalho com as imagens a uma identificação de cenas e personagens e à captação de seus significados mais aparentes e imediatos. De qualquer modo, e por decorrência do que foi dito, permitir-me-ei uma certa concentração de esforços sobre um núcleo de autores mais teóricos que procuram, em seus trabalhos, estabelecer, para além das questões específicas tratadas, um paradigma teórico-metodológico para o trabalho com as imagens em história da Grécia Antiga. Um programa de análise do campo imagético grego surge e consolida-se com esse grupo de autores, merecendo um tratamento diferenciado, que explicite seus pressupostos e instrumentos. Em segundo lugar, não se deixará de chamar a atenção para aspectos relevantes trazidos por outros trabalhos, ainda que não seja possivel detectar em sua diversidade uma identificação, maior ou menor, com esta ou aquela abordagem. A própria coesão do grupo referido acima teria, é bem verdade, que ser relafivizada e assumida em um grau muito genérico de concordâncias. Antes de tudo, o que concilia esses autores é uma concepção da natureza da imagem enquanto
2. Por exemplo, outros dois colóquios: o de Strasbourg, de 1979 , publicado por G.Siebert (1981) sob o título de $M \bar{e}-$ thodologie Iconographique . Actes du Colloque de Strasbourg . E o do Château de Lourmarin, de 1982, publicado como Actes du Colloque sur les probèmes de l'image dans le monde méditerranéen classique, em 1985. 
código de comunicação de valores, de um lado, e, de outro, a consciência de que a compreensão de seus sentidos exige um processo de decodificação, de decifração iconogrática.

A ênfase em tratar a imagem como um sistema de signos criador de significados mostra bem o caráter da mudança ocorrida em setores significativos dos estudos helênicos, especialmente durante a década de oitenta. Mudança que não pode ser atendida senão como uma reação ostensiva a posturas predominantes entre os historiadores no tratamento da imagem e que já não podiam se sustentar face às transformações profundas da historiografia, particularmente a francesa, desde a década anterior. A reação, aliás, é um catalisador importante a agir na convergência de propósitos deste grupo de historiadores da imagem. Vejamo-la um pouco mais atentamente.

A imagem, deve-se dizer uma vez mais, sempre foi utilizada pelos historiadores modernos: pinturas, relevos, esculturas, ilustrações em moedas, tudo isso povoa constantemente suas obras. Mas é justamente a forma de utilização das imagens que gerou o desconforto dos historiadores deste grupo cujas características teórico-metodológicas, em grande parte, constituíram-se sobre uma persistente crítica das posturas então vigentes.

Falando de um modo muito genérico, a imagem ao ser utilizada pelo historiador não obteve melhor sorte do que o restante dos elementos da cultura material. Ambas eram vistas, predominantemente, como fator corroborador de um discurso historiográfico surgido a partir das fontes escritas, sendo aquelas apenas consideradas em função destas. Um agravamento ocorria, todavia, no caso da iconografia: o seu pretenso potencial estético, devidamente processado pela cultura ocidental, reforçava a idéia de que sua função no interior da obra tosse prioritariamente ilustrativa. Aqui uma possivel virtude transformava-se em incapacidade irremediável: o documento, que poderia também ter funções estéticas, deixa de ser documento para exclusivamente aguçar os sentidos.

Nem sempre, porém, o uso ilustrativo prevaleceu. A negligência para com a imagem - assim como para com outros segmentos do universo material - também marcava uma postura que se procurava, agora, superar. Seja como for, é preciso reconhecer que, em última instância e em todos os casos acima (da negligência à ilustração), a iconografia não era utilizada como documento histórico, isto é, não era mobilizada para produzir conhecimento acerca da sociedade que a produziu, na qual circulou, foi consumida, descartada, reciclada, institucionalizada.

Em um dos artigos do Colóquio de Roven, duas estudiosas, P.Schimitt-Pantel e F.Thelamon (1983:9-20) detalham as características desta postura a ser superada e algumas de suas implicações mais importantes. A questão central de todo o problema parece estar ligada às idéias acerca da natureza da imagem visual e, mais especificamente, à sua relação com o trabalho do historiador. Ao ser vista como uma representação direta de uma realidade exterior e objetiva e fornecedora de dados imediatamente utilizáveis, a imagem (ou melhor, esta concepção de imagem) desobrigou o historiador de um esforço de interpretação e impôs ao ofício uma espécie de uso em primeiro grau da imagem: a mobilização de elementos isolados, tidos como auto- 
explicáveis, que remeteriam de modo inequívoco ao fenômeno social que se procura conhecer. Assim, a imagem passava a ser articulada - dentro desses princípios e não de outros - com questões históricas surgidas em territórios alheios a si mesma: a imagem não levantava questões, apenas thes podia servir, e de um modo muito condicionado. A iconografia funcionava, aí, como um depósito ao qual se buscavam imagens úteis para uma argumentação lastreada fundamentalmente em documentos escritos de gênero variado. As implicações mais visíveis de uma tal postura não tardariam a surgir: a referência à iconografia tende à generalização ("como mostram os vasos gregos do século V..."I, dizimando qualquer possibilidade de um uso específico e criterioso; por vezes, a utilização das fontes figuradas é intermediada pelo especialista (historiador da arte, arqueólogo etc.); uma imagem é, no mais das vezes, isolada de uma série (temática, cronológica, espacial) na qual se deveria inserir; há uma tendência a conferir à imagem um valor imanente, menosprezando fatores contextuais, como produção, público, função do suporte físico etc. Estas são apenas algumas das implicações (negativas, sem dúvida) listadas por P.SchimittPantel e F.Thelamon, no referido artigo. As principais, mas não únicas.

O quadro acima é o ponto de referência geral contra o qual vemos, nos últimos anos, cristalizar-se uma forte reação, individual ou institucionalizada, por parte de um considerável número de especialistas em história da Antiga Grécia. A intenção de estabelecer novas bases programáticas para o trabalho com imagens em história permite discernir um grupo de autores (F.Lissarrague; C.Bérard; P.Schimitt-Pantel; F.Thelamon; A.Schnapp; J.-L.Durand; C.Bron; C.Frontisi) cujos trabalhos têm, para além dos objetos tratados, preocupações teóricas e metodológicas explícitas. São os trabalhos deste grupo que permitem perceber com maior clareza as bases conceituais do que poderíamos chamar uma abordagem semiológica da imagem visual (não apenas a fífulo de reuni-los sob um mesmo rótulo, uma vez que este, como veremos, reflete uma característica essencial comum aos autores). São as idéias deste grupo que veremos agora.

Imagem e Semiologia: códigos, significados e decifração

O reconhecimento da inadequação de uma abordagem vigente colocava, como conseqüência inelutável, a necessidade de uma nova proposta que procurasse responder a algumas questões centrais: Qual a natureza da imagem, especialmente da imagem grega? Qual o papel da iconografia no ofício do historiador? Como, e através de que instrumentos, mobilizá-la para a produção do conhecimento histórico? Tratava-se, enfim, de responder como - a partir de que teorias, através de que métodos e com que finalidades - transformar a imagem em matéria-prima documental na construção de um saber específicamente histórico, ou seja, preocupado com a compreensão da estrutura, do funcionamento e da dinâmica da sociedade.

Considerar as novas propostas face a estas indagações parece-me ser o caminho mais seguro para entender as características e avaliar as potencialidades daquelas. 
3. Além dos artigos citados no parágrafo, ver: C. Bérard (1983b).
Algumas respostas gerais foram dadas às indagações acima: a imagem não seria uma tentativa - ora mais ora menos refinada tecnicamente, ora com resultados melhores ora piores - de representação de uma pretensa realidade que the seria exterior e da qual ela seria o reflexo direto; a imagem seria uma composição de signos, criadora de significados; seria o espaço de articulação de unidades formais (icônica) mínimas segundo uma lógica; seria, enfim, um sistema comunicativo. Estas definições, formuladas e aceitas de maneira mais ou menos geral e explícita pelo referido grupo de autores (de um modo mais teórico, poder-se-iam citar: P.Schimitt-Pantel e F.Thelamon 1983; J.L.Durand e F.Lissarrague 1983; C.Bérard 1983 de 1987; A.Schnapp 1987; F.Lissarrague 1987; J.-L.Durand 1987; B.D'Agostino 1987; e, de modo um tanto particular, também C.Sourvinou-Inwood 1987 e M.Constantini 1992) trazem, em seu bojo, implicações sérias para uma delimitação do estatuto da imagem. Em primeiro lugar, porque está a dizer que a imagem não é o decalque da percepção, pretensamente objetiva, que se tem do real sobre um suporte plástico qualquer (vaso cerâmico, mural, mármore...), mas uma composição formada por elementos teoricamente individualizáveis. Em segundo lugar, diz-nos que tal composição não é o resultado de uma sobreposição aleatória de ilustrações, mas um sistema, o que pressupõe a articulação de elementos de acordo com princípios ordenadores. E, por fim, que a articulação sistemática tem uma finalidade: criar sentido, fazer comunicar um significado. A conseqüência de maior abrangência destas considerações é a de que, sendo a imagem uma linguagem, sua abordagem pode (e deve) ser feita através de um método semiológico .

Uma caracterização da proposta de uma semiologia das imagens visuais não poderia deixar de chamar a atenção para o parentesco desta com uma semiologia propriamente lingüística. Vários dos autores citados salientaram a ligação genética entre as duas abordagens. De resto, o próprio vocabulário denunciála-ia: conteúdo narrativo; relação sintática; relação gramatical ; unidades formais mínimas e outros são, todos, conceitos buscados à lingüística para uma aplicação ao campo das imagens. No debate que encerrou o Colóquio de Roven (1983:169s.), P.lévêque sintetiza a questão : assim como, a partir da lingüistica, o texto deixou de ser visto como um elo que nos liga diretamente à realidade histórica, sendo possível, então, atentar para um nível mais profundo do funcionamento da linguagem e buscar o acesso a uma outra realidade (conferindo ao texto sentidos que se podem ordenar em sistemas de articulação complexosl, também no campo dos estudos iconográficos, a idéia é tomar a imagem como uma linguagem que, como tal, produz sentidos que precisam ser decifrados, e que não podem deixar de ser colocados em função do conjunto das relações sociais.

Falar, portanto, de uma semiologia da imagem visual é falar acerca de um conjunto de pressupostos teóricos e procedimentos metodológicos que visam, acima de tudo, a constituição de uma ciência dos significados veiculados plasticamente. Desta forma, a compreensão de um sentido expresso pela imagem torna-se a tarefa precípua de toda a análise iconográfica e é em 
função da consecução desta tarefa que se estabelecem, consequentemente, os instrumentos operatórios.

Metodologia: decomposição e recomposição

O ponto de partida é a identificação e descrição dos elementos que compõem as imagens. $O$ procedimento inicial pode parecer banal, mas é, de fato, mais complexo do que aparenta e, ao mesmo tempo, essencial para as etapas posteriores. Note-se que não se trata mais de identificar elementos nomeáveis (este ou aquele deus, este ou aquele heróil, que já por si seriam conjuntos complexos de significado, mas de discernir no corpo das imagens os elementos icônicos mínimos que a compõem, estabelecendo um repertório de unidades formais com potencialidade atributiva las vestes, a barba, os traços fisionômicos, o altarl $\left.\right|^{4}$. Ademais, não é uma tarefa que se esgoła em si, como é freqüente ocorrer alhures, e sim uma etapa preliminar que visa fornecer uma base segura, a partir da explicitação dos elementos icônicos mínimos, para o estabelecimento posterior das relaçōes sintáticas entre eles.

Assim, em um dos artigos, de J.-L.Durand e F.Lissarrague (1983:153167), o estabelecimento dos elementos icônicos de uma série de vasos onde é representada a tentativa de sacrifício de Héracles, no Egito, a mando do faraó Busiris, permite aos autores mostrar como é que o discurso imagético se constrói praticamente com os mesmos elementos das representações de sacrifícios canônicos no mundo helênico. É, entretanto, na combinação destes elementos que se vai criando um outro modelo iconográfico do sacrifício, distinto do primeiro.

Mesmo nas tentativas de identificação de personagens, o estabelecimento dos elementos constitutivos da imagem ganha uma outra dimensão: as unidades formais mínimas (traços, objetos, signos enfim) aparecem como componentes que perfazem subsistemas (uma personagem, por exemplo) no interior do sistema geral da cena, conferindo àqueles significados parciais, tendo, portanto, caráter atributivo.

Em um outro artigo, de M.C.Villanueva Puig (1987:131-139), a autora mostra como a definição de certos elementos icônicos mínimos (peixes, ramos de videira, cestas de flores) é fundamental para distinguir entre Europa e as Mênades, nas representações de uma mulher assentada sobre um touro em vasos áticos de figuras negras. Por oposição, outra autora, A.F.Laurens (1987:59-72), mostra que a identificação daqueles elementos não é suficiente para se saber com segurança quem é a figura feminina que aparece ladeando Héracles e que só pode ser relacionada com Hebe a partir de sua convivência, na cena, com outros subsistemas que the conferem sentido. A insuficiência é, aliás, proposital: a figura de Hebe é construida (e reconhecida culturalmente) como a imagem arquetípica da rapariga jovem, sem gestos ou atributos próprios, que só é definida iconográfica e socialmente pela sua conjugação
4. Não é sem motivo que C.Bérard (1983a:111s) chama a atenção, elogiosamente, para uma obra de M.R. Salomé, o Code pour l'analyse des représentations figurées sur les vases grecs. E menos por sua proposta de um banco de dados do que pela sua contribuição no que concerne a uma descrição precisa e regular dos elementos constitutivos das representações figuradas, recusando qualquer identificação prévia e estabelecendo uma "base cientifica para uma semiologia da imagem". É significativo que o Código, elaborado em 1965, venha a ser publicado em 1980. 
5. C.Bérard e J.L. Durand (1984:19). com outros conjuntos que the definem um contorno, uma identidade precisa fo marido, por exemplol. Os mesmos procedimentos podem ser vistos também na identificação de seqüências narrativas e não apenas de personagens, como é demonstrado por uma terceira autora, C.Bron (1987:145-153), em seu trabatho sobre as cenas do ritual de iniciação de uma bacante.

A tarefa de identificação, assim, ganha espaço no interior de um conjunto de procedimentos analíticos objetivando a busca de um significado da imagem, deixando, pois, de ter importância por si mesma. Já se alertou, ademais, para o fato de que a vontade exarcebada de identificação das figuras foi responsável por um viciamento da interpretação e que, de todo modo, nem sempre aquela se apresenta como um pressuposto indispensável desta ${ }^{5}$.

Em qualquer dos casos, é preciso salientar que a criação do significado (afinal, o que mais importa) tem sua matriz na articulação dos elementos icônicos, ou seja, no momento de uma conjugação sintática das unidades gramaticais. É um processo, de fato, realizado em estágios, como nota C. Bérard (1983b:7): algumas unidades formais mínimas (pele de leão, clava, barba) são combinadas para criar um sintagma mínimo, portanto, já um primeiro nível de significação. Este sintagma mínimo, ao se articular com outros, compõe uma imagem de conteúdo narrativo e nos remete ao espaço de significação de uma cena tal qual a de Héracles capturando o javali de Erimanto. Tal processo, o da passagem de uma relação de referência a uma relação de significação, é o coração da análise iconográfica de orientação semiológica.

No que consiste a articulação dos elementos icônicos mínimos? $\bigcirc$ que é esse passo tão importante no processo de criação do significado? Em uma palavra, pode-se dizer que se trata das diversas formas de composição de um todo imagético lou de constituição de uma unidade iconográfica mais complexa pelas unidades menores disponíveis e buscadas a um repertóriol. Para o historiador que trabalha com imagens, trata-se, conseqüentemente, de explicitar e compreender os diversos meios de arranjo das partes na formação de um todo, e, nos casos mais otimistas, desvendar as leis que regulam os procedimentos de formação da imagem neste momento crucial da articulação das unidades icônicas mínimas. Metodologicamente falando, está-se percorrendo um caminho inverso daquele trilhado no momento inicial da análise: lá, o estudioso decompunha a imagem no intuito de discernir os elementos formais mínimos e, isto feito, construir um repertório, proceder a uma taxonomia, ordenar e classificar o material; já aqui, procura-se ver os mecanismos que nortearam a combinação das unidades para a formação da cena. Lá, houve um desmonte ideal; aqui, uma recomposição, também ideal, da imagem.

Mas do que se constitui esta articulação geradora de sentidos, na qual a análise concentra, agora, sua atenção? Ver-se-á que muitos são seus componentes: associação de elementos (pares, tríades...); distribuição dos elementos no espaço; hierarquização das unidades mínimas; exclusão etc. Alguns exemplos concretos tornarão mais clara esta elapa do trabalho semiológico com a imagem.

Analisando uma série de vasos nos quais aparece a representação 
parte das formas de articulação dos elementos na imagem para chegar aos significados por ela veiculados: significados relacionados ao consumo do vinho e aos valores a ele associados. O autor mostra como a presença ou ausência de elementos (centauros) pode criar, ou não, uma perturbação da ordem cênica, gerando sentidos diversos la possibilidade ou não da efetivação dos valores da hospitalidade) $\left.\right|^{6}$. Ou, de outro lado, como a disposição espacial dos elementos em duas cenas do mesmo vaso pode indicar, na primeira, o preenchimento das condições para uma circulação harmônica do vinho e, na segunda, uma impossibilidade de circulação, com todas as implicaçōes daí advindas para a realização das formas elementares da sociabilidade humana: o consumo compartilhado do vinho lem certos vasos, a exclusão de alguns elementos e a composição daqueles que aparecem representados constroem o caráter a-social de Héracles, banqueteador solitário, garçom de si próprio, privado de convivas) ou a hospitalidade lem uma das cenas de uma taça, por exemplo, uma tropa de centauros corre em direção à outra cena, onde Héracles se apropria de seu jarro de vinho, introduzindo aí uma conturbação indicadora da impossibilidade de uma relação de hospitalidade fundada na circulação do vinho). Neste último caso, a análise de outras componentes do arranjo - fixidez/movimento - são fundamentais.

Em um outro estudo, de dois autores já muito citados aqui, J.L.Durand e F.Lissarrague 150-167), sobre as cenas de tentativa de sacrifício de Héracles pelos egípcios, a ênfase é também colocada na presença ou ausência de certos elementos la presença de objetos gregos em um sacrifício egípcio, indicando a utilização de um esquema iconográfico já existente e seu transporte para um outro confexto) e na organização geral do espaço (o altar se constitui como ponto de divergência, organizando a cena de modo centrífugo e reforçando o desmantelamento do significado ritual do sacrifício).

Um outro fator de grande importância na análise da articulação das unidades icônicas foi salientado por F.Frontisi-Ducroux (1987:89-102): o redobro, isto é, a repetição de um mesmo elemento, criando possibilidades de significação diversas: efeito de intensidade; intenção de conotar a dualidade do ser figurado ou de valores a ele ligados; tentativa de perfazer um todo pela dupla representação de uma parte. No mesmo artigo e, especialmente, em outro, de C.Calame (1987:79-88), chama-se a atenção para a posição das representações de indivíduos ou máscaras. Não apenas a observação atenta da frontalidade ou do caráter perfilado da figura, mas também a organização das direções dos olhares, são fundamentais na busca das intenções de significação, dos modos de comunicação de valores. As direções do olhar colocam o seu portador em relação com as demais personagens da cena bem como com o próprio receptor externo. Desta forma, os olhares transformam-se em elementos gramaticais indispensáveis na construção sintática da iconografia. Da mesma forma os gestos e feições fisionômicas têm igual papel (P.Ducrey 1987:201-212 e C.Bron 1987: 145-154), apontando mesmo para a necessidade da constituição de um corpus de gestos da Grécia Antiga.

Gostaria, ainda, de chamar a atenção para um último fator desta operação de articulação das unidades mínimas, cuja compreensão parece ser
6. A questão da exclusão ou inclusão de elementos na constituição de uma cena está intimamente ligada aos procedimentos de escolha presentes na composição da imagem que, por sua vez, manifestam intenções, mais ou menos conscientes, de criar significados, comunicar mensagens. Cf. M.C. Villanueva Puig (1987:131-144). 
de muita importânicia para o entendimento do processo de criação de significado. $O$ trabalho de análise da composição das imagens, e das operações a ela inerentes, pode levar o estudioso à constituição de esquemas estruturais, ou seja, formas mais ou menos estáveis e recorrentes utilizadas para a representação de determinados motivos. Os exemplos abundam: há um esquema para a figuração da procissão nupcial, outro para a cena de partida do guerreiro e assim sucessivamente. Pois bem, ocorre que, em muitos casos, o pintor utiliza-se de um esquema já consagrado na iconografia introduzindo nele novas unidades individuais ou novos conjuntos de elementos. É o caso estudado por A.Verbanck Piérard (1987:187-200): os pintores dos vasos de figuras negras do século VI introduzem em modelos já conhecidos de representação dos deuses (festas divinas, o desfile na quadriga) a figura de Héracles. Através deste mecanismo de "empréstimo", os artistas orientavam deliberadamente a imagem do herói para o espaço divino, junto aos imortais e, particularmente, aos deuses protetores da cidade de Atenas. Os pintores áticos reconheceram uma distorção entre o seu repertório antigo e o novo culto a Héracles e procuraram, então, pela inclusão deste em esquemas anteriormente exclusivos dos deuses, consolidar, também no nível iconográfico a transição do Hêrós ao Théos. Mas isto não significa que a iconografia apenas reflita um fenômeno ritual que the é exterior: é interessante ver como a associação entre Héracles e a deusa Atena, que parece não ter existido cultualmente, é transformada em um elemento central de um mecanismo imagético de criação de sentido, que busca divinizar o herói pela justaposição de sua imagem à da deusa protetora, no interior de esquemas iconográficos determinados. No fundo, o que vemos, aqui, é o funcionamento de um processo de articulação de elementos mínimos para a criação de sintagmas que, por não serem fixos, podem servir à criação de campos icônicos diferentes, gerando sentidos também diversos (C.Bron 1992:47-84).

. Os exemplos acima mostram a variedade de operaçōes que compõem esta fase de articulação dos elementos icônicos mínimos. Fase fundamental na qual se concentra a produção de significados no processo de construção da imagem e que, por isso mesmo, deve, segundo os autores analisados, ser objeto de detida atenção por parte do historiador. Os diversos modos de combinação das unidades formais constituem, assim, a chave para penetrar no sentido da imagem.

Contaminações e influências

É de se notar que, dentre os autores citados logo acima, muitos não fazem parte nomeadamente daquele grupo que identificamos a princípio e que se caracteriza pelas intenções programáticas mais explícitas. Ao contrário, este segundo grupo de artigos (D.Noel 1983; O.Touchefeu 1983; A.F.Laurens 1987; C.Calame 1987; A.Verbanck Piérard 1987; P.Ducrey 1987; J.Bazant 1987; F.Frontisi-Ducroux 1987; M.-C.Villanueva-Puig 1987; C.Bron 1987. 
C.Miquel 1992; J.L.Durand 1992; C.Bérard 1992; C.Bron 1992; A.Pomari 1992; I.Manfrini-Aragno 1992/ caracteriza-se menos pela teorização do que pela aplicação prática, em casos específicos, dos preceitos estipulados pelo, chamemos assim, grupo teórico. Isto demonstra, em primeiro lugar, que as propostas de uma abordagem iconográfica de caráter semiológico tiveram um efeito contagiante, extravasando o núcleo teórico inicial e pautando as pesquisas de diversos estudiosos da imagem e da sociedade gregas. Em segundo lugar, aponta para uma predominância inequívoca, no conjunto dos trabaThos examinados, de uma abordagem semiológica da imagem, não apenas pela quantidade de artigos que a desenvolvem mas também pela razoável unidade de propósitos e procedimentos de seus praticantes ${ }^{7}$.

Não obstante este predomínio de uma abordagem semiológica, uma série de outros trabalhos trazem contribuições tópicas, por vezes importantes, muito embora não se possa identificar neles um conjunto coeso ou uma segunda tendência interpretativa. Um desses casos é o artigo de M.Vickers 11983:29-42), onde é trabalhada uma questão central da criação das imagens: as cores. $\bigcirc$ autor expõe sua polêmica tese de que as combinações cromáticas presentes nas duas técnicas centrais da pintura cerâmica ática - figuras negras e figuras vermelhas - são decorrentes de uma busca de imitação dos metais preciosos lassim como os lécitos de fundo branco procurariam imitar - marfiml, e não de uma imposição das condições técnicas ou do acaso. Apesar das oposições que tal hipótese suscitou (cf́. a intervenção de B. Shefton no debate final no Colóquio de Roven, p.1731, ela tem o mérito de articular o problema das cores com pelo menos três aspectos significativos: al as limitações impostas, por vários motivos (gastos de guerra, por exemplo), à confecção de vasos em metal: a combinação das cores em vasos cerâmicos seria o resultado de um esforço de substituição mimética dos vasos metálicos; b) a relação entre a artesania metálica e a cerâmica: a influência indo da primeira para a segunda, não apenas no que diz respeito às cores, mas também às formas; cl por fim, de modo apenas sugestivo, as relações simbólicas entre cores e valores sociais.

Entretanto, a grande maioria dos artigos situados à margem do grupo semiológico (ou de sua zona de influência) concentra-se em questões que se distanciam de uma análise dos elementos constitutivos da imagem e de suas formas de articulação. A ênfase é dada ora à indagação acerca da origem e trajetória de um esquema iconográfico ou às relações genéticas entre imagens e à influência dos grandes pintores (S. Woodford 1983:121-129), ora às indagações acerca da potencialidade reflexiva da imagem em relação aos fenômenos sociais (D.Williams 1983:131-140), ou ainda ao estabelecimento de cronologias, (M.Vickers 1987:19-25).

É significativo que nenhum desses autores seja de língua francesa, o que apenas reforça um certo caráter franco-suiço da abordagem semiológica.
7. A vitalidade da abordagem semiológica, cristalizada teórica e metodologicamente durante a década de oitenta, pode ser medida por um de seus mais recentes produtos, um longo capítulo de F.Lissarrague sobre a iconografia da mulher na Grécia Antiga, publicado em M.Perrot e G. Duby, orgs, (1991: 159-251). E, de fato, um magistral exemplo do emprego da análise semiológica em uma problemática delimitada, a imagem da muIher. Todos os procedimentos aqui evocados como característicos da abordagem semiológica aparecem, neste trabalho, de modo claro e em abundância, com uma vantagem: as implicações históricas da análise iconográfica são mais presentes e sistemáticas que nos artigos aqui examinados. 
8. Uma das autoras, M.S. Lagrange, já aplicara, anos antes, um procedimento parecido em outra área, a da história da arte, empreendendo uma análise de decodificação semiológica, por via computacional, a um texto tomado como campo de testes (no caso, o Recueil de plans d'églises cisterciennes, de A. Dimier). A intençâo era mostrar como, mesmo em uma obra tida como sistemática e objetiva, interferem inúmeras considerações subjetivas, que poderiam ser detectadas e controladas pelo método semiológico e por um tratamento computacional. M-S. Lagrange -. Analyse sémiologique et bistoire de l'art. Paris, 1973.
Um grupo de artigos que merece uma rápida consideração em separado é o que trata das possibilidades de aplicação do computador ao estudo das imagens. Três dos cinco artigos sobre o assunto, todos do Colóquio de Rouen, apresentam uma característica em comum: são comunicações acerca de projetos que procuram facilitar as condições de trabalho com o imenso corpus iconográfico grego, através do auxílio do computador. Em um dos casos (R.Glynn 1983:67-791, trata-se de um arquivo das informações bibliográficas sobre os vasos, uma versão computadorizada dos trabalhos de J.D.Beazley (Beazley Archive Computer Project). Em outro trabatho (V.C.Di Bari e G.OrsoliniRonzitii 1983:81-901, algo semelhante ao anterior, realizado, desta feita, com o Corpus Vasorum Antiquorum. Em um terceiro artigo (L.Villard 1983:9197) trata-se ainda de um banco de dados, porém, com duas vantagens sobre os anteriores: as informações têm como base o próprio objeto e não a bibliografia pertinente (que não é, todavia, desprezadal e o campo é bem mais abrangente (vasos, mosaicos, estátuas etc.). Em todos os casos, contudo, as propostas limitam-se às vantagens técnicas advindas da substituição de um trabatho manual por um computadorizado, sem qualquer implicação para o processo interpretativo em si. Uma vez que o computador não é incorporado pelos seus potenciais analíticos, o seu papel reduz-se às suas qualidades arquivísticas (maior capacidade de armazenagem, maior rapidez na consulta dos dados). Essas limitações foram sentidas pelos próprios participantes do Colóquio lassim, Metzler chega a comparar o procedimento ao mesmo que Lineu utilizava na biologia do século XVIII, p. 174).

Um quarto artigo tratando do tema é, porém, muito interessante. As autoras, M.S.Lagrange e M.Renaud (1983:43-66), propõem testar, por via computacional, o processo de raciocício em arqueologia, através de uma simulação do comportamento interpretativo do arqueólogo. As vantagens de um tal programa (SNARK) seriam, para as autoras, de grande proveito: em primeiro lugar, permitiria avançar no conhecimento dos modelos gerais de raciocínio em arqueologia; depois, obrigaria a uma formulação mais rigorosa dos conceitos e das operações; além disso, incitaria o arqueólogo a uma reflexão crítica sobre súa atividade. Como se vê, a preocupação com uma sistematização dos modelos operatórios e das cadeias de inferência, de modo objetivo e até mesmo matemático, responde a muitas das preocupações surgidas, inicialmente, no âmbito da chamada New Archaeology e apontam no sentido da consolidação de um procedimento científico similar ao das ciências exatas no campo da arqueologia ${ }^{8}$.

Um último trabalho interessa-nos mais de perto, pois se trata da transposição dos princípios estabelecidos pelo grupo semiológico para o nível computacional. O artigo (F.Viret Bernal F.Vallotton A.Rogger e C.Bron 1992:173188) trata da aplicação de um programa de inteligência artificial, desenvolvido com o auxilio da Escola Politécnica da Universidade de Lausanne, cuja finalidade é ajudar na identificação e interpretação das cenas pintadas em vasos áticos do século $\mathrm{VI}$ ao $\mathrm{V}$ a.C. $O$ programa foi batizado de TIRESIAS /Traitement informatisé de reconnaissance des éléments sémiologiques pour l'identification analytique des scènes). As intenções são as mesmas dos procedimentos semiológicos anteriores: isolar os elementos constitutivos da imagem e explicitar as regras lógicas que presidem sua composição (p. 173). 
Para tanto, o método (transposto para o programa computacional) parte da identificação das unidades formais mínimas e da constituição de um repertório de elementos; verifica, após, a composição de sintagmas que estabelecem uma relação de significados entre os elementos e, por fim, procura reconhecer as regras de articulação que constituem a cena (p. 184).

Reconheça-se, aqui, a rapidez e objetividade introduzidas nos problemas de identificação de uma personagem ou de uma cena, mas, ao mesmo tempo, registre-se um certo ceticismo em relação às possibilidades de incremento dos procedimentos analíticos da iconografia e, especialmente, em relação à capacidade de, a partir de um tal programa computacional, avançar na interpretação histórica da imagem.

Imagens para qual história?

Ainda em relação ao predomínio de uma abordagem semiológica, nos colóquios examinados, uma última questão merece ser tratada. A mobilização de imagens se dá em função de que problemas historiográficos? Quais tipos de temas prevalecem em uma tal abordagem?

P.Schimitt-Pantel e F.Thelamon, em um dos artigos mais programáticos do grupo semiológico (1983:9-20), lembram que as potencialidades do estudo das imagens são diversificadas, permitindo a reflexão sobre as práticas sociais (a estrutura do trabalho, por exemplo), sobre as representações mentais (a ideologia da guerra, a visão do outro etc.) e, ainda, podendo influenciar nos debates historiográficos sobre temas diversos (a 'reforma hoplítica 'e sua influência nas relações políticas, entre tantos outros). Entretanto, uma observação quanlitativa mais atenta das comunicações apresentadas fará minimizar esta presumivel pluralidade potencial em benefício de uma efetiva concentração em temas que poderíamos agrupar sob o rótulo genérico de "mentalidades" . É verdade que o colóquio de Roven reservou, por uma orientação prévia, todo um esforço ao estudo das imagens relativas à mitologia de Héracles, mas tal fato não explica a concentração aludida acima, seja porque ela também ocorre nos demais encontros, seja porque a delimitação em torno das imagens de Héracles não implicaria necessariamente uma dedicação exclusiva a temas ligados à história das mentalidades. Certamente, as razões desta visível predominância devem ser buscadas em contextos mais amplos. Nascida no ambiente acadêmico francês, impregnado na década de oitenta com a consolidação de uma história social das mentalidades, não é estranho que a iconografia semiológica se tenha constituído sob o signo imperativo do estudo de fenômenos ligados àquele campo. De resto, estava-se reproduzindo, no nível dos estudos iconográficos, o que já ocorrera com uma das principais tendências da historiografia francesa, a École des Annales, e, em escala mais específica, com o Centre de recherches comparées sur les sociétés anciennes, de Paris, sob a influência de J.P.Vernant9.
9. O próprio J.P.Vernant participara diretamente dos esforços para transformar a imagem em campo de exploração do historiador. Cf. sua introdução a La cité des images (Vernant, 1984) 
Alguns motivos, relativos, à própria natureza da imagem, poderiam ser enumerados para explicar a atenção privilegiada aos temas de história das mentalidades. A maioria deles pouco convincentes, como vimos (o fato de uma grande parte das ilustrações serem voltadas a temas mitológicos, por exemplo). Um argumento, todavia, parece ter exercido um peso considerável, pois estabelecia as condições de compatibilidade entre as próprias definições de imagem e mentalidade: em um texto já célebre, M.Vovelle (1979:6) pondera que o potencial que as fontes iconográficas oferecem ao estudo das mentalidades advém principalmente do fato de aquelas parecerem, de certo modo, mais "inocentes" ou mais reveladoras que o discurso oral ou escrito, de modo que delas se pode esperar extrair significaçōes dificeis de serem buscadas em outros tipos de fontes. A iconografia revela-se, assim, como uma "confessora involuntária" das intimidades da mentalidade de uma época. Os autores do grupo semiológico tendem a professar tais princípios, quer teoricamente |C.Bérard 1983a:176: a iconografia é o lugar privilegiado da projeção e do desenrolar do imaginário sociall), quer empiricamente, como demonstram vários dos trabalhos. A iconografia, por seu caráter anônimo e coletivo (C.Bérard 1983b:51, foi considerada, enfim, o material documental privilegiado onde se buscar elementos para o estudo das mentalidades, não menos anônimas e coletivas que a própria imagem que as veicularia.

Note-se que as conseqüências desta tendência de concentração não determinaram a exclusão absoluta de outros temas. Por vezes, o resultado é mais complexo e curioso: o predomínio de temas de história das mentalidades age no sentido de estabelecer uma certa forma de tratamento a questões que, a princípio, não seriam típicas deste campo /de qualquer modo, os limites do que sejam as mentalidades são muito pouco claros). Em outras palavras, ao tratar de temas relacionados, digamos, à história das relações de poder, a partir das imagens, são salientados aspectos de representações mentais aí envolvidos. A comparação entre dois artigos pode ser esclarecedora a respeito. De um lado, D.Williams (1983:131-140) procura mostrar as relações existentes entre a propagação de certas imagens de Héracles e as contingências políticas da cidade de Atenas, no século Vl a.C., salientando aspectos da intencionalidade propagandística de grupos partidários (os seguidores de Psístrato e os Alcmeônidas) e a funcionalidade ideológica das imagens. De outro lado, J.Bazant (1987:33-40), ainda que tratando de um tema semelhante - a relação entre as representações em vasos áticos e as reformas democráticas - coloca, diversamente, o acento sobre as representações sociais ligadas a valores da mentalidade guerreira e aristocrática ou de um ideal cívico comunitário, além dos diferentes aspectos simbólicos das figurações de mulheres, heróis ou jovens, decorrentes da tensão entre aqueles dois paradigmas, o aristocrático e o democrático.

Em resumo, mesmo em se tratando de temas políticos, a abordagem semiológica parece ter imposto um predomínio das preocupações características da história das mentalidades, em detrimento, por exemplo, de uma análise institucional das relações de poder. É de se notar, aliás, o ceticismo demonstrado por autores como F.Lissarrague, P.Schimitt-Pantel e G.Donnay, no debate que finalizou o colóquio de Roven (p.183ss.), acerca das possibilidades do uso da 
imagem para o estudo de questões políticas. P.Schimitt-Pantel é contundente ao dizer que o político, como tal, não seria traduzível na imagem (p. 184)10.

Duas considerações devem ser feitas a este respeito. Primeiro, que, apesar de questionarem a idéia da imagem como reflexo de outros fenômenos sociais, os autores do núcleo semiológico raramente conseguiram perceber todas as implicações de encarar-se a imagem, ela mesma, enquanto fenômeno social; uma das conseqüências disto foi ter-se dado conta apenas timidamente do papel da imagem enquanto elemento ativo do processo social e de suas potencialidades como vetorizadora de interesses e anseios políticos, quer individuais quer de grupos. Em segundo lugar, é preciso observar que, no fundo, não houve uma prioridade a temas ligados à história das mentalidades, como opção teórica prévia. O caminho percorrido foi diferente: partiu-se de uma seleção de fontes que, por sua vez, condicionou os temas a serem tratados. $O$ conjunto das problemáticas é mais uma conseqüência dos corpora documentais do que de preocupações historiográficas.

Fontes, imagens e texto

Uma última questão será objeło de consideração - a relação entre imagens e textos, bem como entre as formas de conhecimento produzido a partir de cada um. Tal foi a preocupação cental de um dos colóquios examinados, o de Chantilly, mas está presente também nos demais encontros. Vimos, no início, que o esforço por conferir à imagem um estatuto próprio de fonte histórica estava nas raízes das propostas dos estudos iconográficos, em geral. Uma reação, também vimos, ao caráter ilustrativo imposto à imagem e ao seu lugar secundário, ancilar e corroborativo na construção do conhecimento histórico. De certa forma, pode-se dizer que qualquer valorização da imagem enquanto material de estudo passava, forçosamente, não apenas pelo estabelecimento de seu status, como também de sua posição face aos demais documentos já consagrados, ou seja, as fontes escritas de toda ordem. Outrossim, cabia também estabelecer, mais praticamente, as relações entre fontes textuais e iconográticas no interior das operações de interpretação, estabelecendo critérios de autonomia, interdependência, dependência, hierarquia das potencialidades e de confiabilidade etc.

Uma das características distintivas da maioria dos trabalhos do chamado grupo semiológico foi conferir uma grande autonomia às fontes iconográficas. A concentração na análise minuciosa das imagens fez, em geral, com que os textos fossem considerados de um modo subsidiário. A autonomia da imagem enquanto uma linguagem específica correspondeu uma tendência a conferir independência ao documento iconográfico frente ao textual. A tal ponto essa tendência foi sentida que O.Touchefeu (1983:21-27) chamou a atenção para os perigos de se substituir uma visão tradicional, que fazia da imagem uma figuração do texto, por outra, na qual se recusasse o conhecimento do
10. Saliente-se, uma vez mais, que os dois artigos que procuram trabalhar temas politicos com base em fontes iconográficas, de um modo destoante da proposta semiológica, são, ambos, em lingua inglesa: além do de D.William, o de S. Woodford (1983: 121129), cuja origem é, sintomaticamente, um trabalho da pesquisadora para um verbete do Lexicon Iconograpbicum Mytbologiae Classicae, de orientação tão diversa em comparação com os trabalhos do grupo semiológico. 
texto e se evitasse o paralelismo entre os dois tipos de fontes. A questão encaminhara-se, como se vê, para as considerações sobre a relação entre imagem e texto no interior do contexto de sua produção: Até que ponto, na Grécia Antiga, a primeira é transposição, em outro código, do segundo? $\mathrm{E}$, por decorrência, até onde pode o historiador atuar no sentido de complementar as lacunas textuais pelas informações da imagem (e vice-versa)? $\bigcirc$. Touchefeu mostra, justamente, um caso que evidencia as fragilidades de uma comparação nesse nivel: a narrativa da morte de Astíanax, neto do rei Príamo, de Tróia, como aparece na llíada de Homero la criança sendo jogada do alto das muralhas, quando da invasão da cidadel e as representações em vasos de figuras negras ou vermelhas, de 570 a 460 a.C. Inas quais um guerreiro grego aparece matando o neto aos pés de Príamo ou jogando-o, já morto, contra o avôl. $O$ mesmo caso é examinado em outro trabalho, de A. Pomari (1992:103-1251, que mostra como as tradições são conflitivas mesmo entre a literatura e chama atenção para um aspecto interessante da convivência de vários sistemas comunicativos na sociedade grega: o historiador não pode esperar que o observador da época sempre e mecanicamente se baseasse nos textos para decifrar a cena dos vasos, podendo este apelar para um conhecimento do conjunto da iconografia e das convenções gráficas para decifrar a imagem (p. 105).

Assim seria ilusório buscar, em cada caso, a chave textual para adentrar na imagem. Para a maioria dos autores do núcleo, situações como essa mostrariam, em primeiro lugar, a necessidade de uma interação que buscasse ir além da obtenção de informações primárias; em segundo lugar, que, muito embora linguagens, texto e imagem requerem instrumentos de análise adequados às suas especificidades; em terceiro, que as potencialidades não são idênticas e as hierarquias devem ser estabelecidas caso a caso; por fim, que a análise da imagem não deve ficar dependente de qualquer condicionante proveniente do trabalho com os textos, ainda que este possa oferecer insights iniciais.

Os condicionamentos, aludidos acima, parecem provenientes, antes de mais nada, de uma tentativa superficial de interação entre fontes iconográficas e textuais, onde se procura prioritariamente suprir as lacunas informativas existentes em uma com o recurso à outra. Dai alguns trabalhos chegarem à conclusão de que há uma grande dificuldade em cumprir tal tarefa ou mesmo creditarem os problemas a uma deficiência intrínseca da imagem la falta de conteúdo narrativo, por exemplo). É o que ocorre com F.Jouan (1984:61-74) ao tentar resolver questões relativas ao sacrifício de lfigênia, surgidas a partir do texto de Eurípedes, recorrendo às representações ilustradas. É de se notar que mesmo quando o material proporciona compensações mútuas de informações, o resultado é apenas a confirmação (ou não) de uma hipótese construída a partir de uma das séries documentais. As comprovações mútuas - textuais e iconográficas - atuam apenas no nível dos resultados informativos, não estabelecendo uma verdadeira interação dos procedimentos operatórios para a produção de um conhecimento baseado em textos e imagens lé o caso do artigo de L.Kahil 1984:53-60, que procura uma comprovação mútua do caráter da deusa Ártemis, na Átical. 
Não se deve concluir apressadamente, entretanto, que qualquer trabalho com duas séries paralelas de documentos seja inútil, especialmente se a simples busca de dados complementares ceder espaço para as comparações analíticas. O reconhecimento de que a imagem tem funções próprias /ainda que interligadas) no conjunto das relações sociais é um importante passo para tratar a iconografia como um registro documental independente, com suas próprias características. Desta forma, ainda que se reconheça, por exemplo, a influência do texto homérico na produção imagética, dever-se-iam analisar, na iconografia, aspectos relativos às formas de processamento daquela influência. $O$ parentesco entre texto e imagem não retira desta, necessariamente, seu caráter simbólico. A imagem funciona em níveis diferentes de criação, comunicação e recepção de sentidos. Assim, se, na epopéia, o suicídio de Ajax é uma cena narrativa, na imagem pode tornar-se símbolo do destino do herói e da armada grega (K. Schefold 1984:40-52).

E importante ressaltar a diversidade dos níveis de funcionamento dos diversos sistemas comunicativos, pelo menos por dois motivos: primeiro, para evitar-se uma assimilação mecânica da escrita com conteúdos verbais, de um lado, e, de outro, da imagem com conteúdos não narrativos; segundo, para sublinhar o fato de que os instrumentos operatórios não são sempre previamente definidos pela natureza de um código, mas também pelo funcionamento deste código em um contexto documental. Um dos trabalhos de F.Lissarrague (1992: 189-202) busca, justamente, mostrar como a inserção das inscrições no campo imagético, fato comum em vasos gregos, nem sempre foi um artifício de auxílio para a compreensão da cena ou identificação de uma personagem. Por vezes são os atributos gráficos da inscrição que dẹfinem seu papel no interior da imagem e não o conteúdo lingüistico que lhe subjaz. Particularmente antes de meados do século $V$ a.C., a inscrição insere-se na cena como um de seus elementos figurativos e não como um código paralelo e diferente. Em situações como essa, a análise da escrita poderia, para o autor, recorrer aos mesmos instrumentos semiológicos.

A imagem na história, a história na imagem

Uma consideração final sobre o movimento de inserção da imagem no horizonte do historiador poderia levantar uma série de questões específicas relativas à qualidade das propostas teóricas e metodológicas dos autores do grupo semiológico. Limitar-me-ei, entretanto, apenas a lembrar uma questão de âmbito geral, que me parece fundamental.

Foi dito, no início deste balanço, que a grande mudança de postura ocorrida na historiografia, no decorrer dos anos setenta e oitenta, fora a definitiva apropriação da imagem como fonte para a construção de um saber especificamente histórico. Os problemas levantados por esse movimento levam-nos ao centro de uma das mais sérias preocupações do debate historiográfico contem- 
11. Como já se observou, a presença de problemáticas históricas é, em geral, uma decorrência dos corpora documentais tratados e só existem em função deles. Isto não implica, absolutamente, a ausência de preocupações hiștóricas. Em dois artigos sobre a mulher (o de F.Lissarrague, já citado na nota 7 e o de I. ManfriniAragno), 1992:127148 , a presença de um tema bem delimitado é clara. Estes, porém, constituem exceções. porâneo. De fato, a "documentalização" da imagem (isto é, sua inclusão como fonte de um processo de produção de conhecimentol não gera apenas a necessidade de responder às novas indagações práticas colocadas ao historiador; colocam problemas que vão além de estabelecer técnicas que tornariam as interpretações confiáveis. Há, ainda, uma outra questão, de fundo epistemológico: qual o tipo de relação possível (e aceitável para o historiador) entre os vestígios (aqui, iconográficos) e o conjunto de fenômenos históricos estudados? Como o discurso historiográfico deve compor a relação entre as representações visuais e a sociedade?

Qualquer tentativa de trabalho com a imagem em história terá, obrigatoriamente, que responder a essas questões. Terá que estabelecer o espaço documental da iconografia e, a partir daí, definir qual seu papel na pesquisa histórica.

É inegável, pelo exame aqui feito, que houve uma inequívoca intenção de transformar a imagem em matéria-prima documental. E menos pelo fato de os promotores desse deslocamento serem historiadores do que pela sua mobilização em função de indagações históricas ${ }^{11}$ e do tratamento a que é submetida. O que cabe perguntar, pois, é se os caminhos seguidos foram adequados a essa intenção inicial ou, mais explicitamente, como que o predomínio de uma abordagem de caráter semiológico se comportou em relação ao processo de "documentalização" da imagem: os procedimentos operatórios, derivados de uma abordagem semiológica da imagem visual têm pertinência para um trabalho de compreensão da sociedade?

Não me parece restarem dúvidas acerca das contribuições da semiologia para um melhor conhecimento da imagem. Entretanto é preciso reconhecer que o entendimento do funcionamento da imagem, dos seus mecanismos articuladores e de seu processo de criação de sentidos não, são suficientes para estabelecerem, por si, o caráter documental da imagem. É necessário, ainda, estabelecer a ponte que liga a análise iconográfica ao estudo de problemas históricos. É preciso pensar o elo entre as produções de um conhecimento da imagem e um conhecimento da sociedade. $O$ processo de interpretação exige a inserção do documento iconográfico no interior do contexto no qual tivera existência enquanto elemento material e visual de uma cultura, um contexto no qual ele fora, a um só tempo, produto e vetor de relações sociais. $O$ que se poderia opor à análise semiológica é, principalmente, o fato de ter promovido uma concentração de esforços na intelecção do objeto iconográfico em si, apartando-o do contexto histórico que the conferia significado. Daí uma série de deficiências que poderiam ser rapidamente enumeradas: em primeiro lugar, uma certa desconsideração pelas condições sociais de produção, circulação, consumo etc., isto é, pelos aspectos da trajetória da imagem le de seu suporte físicol na sociedade, em benefício de uma visão pontual e estática do objeto visual. Em segundo lugar, decorrente em parte da anterior, o esvaziamento da historicização da imagem, especialmente através da clivagem perpetrada entre ela e os seus vetores sociais, o que privilegia uma análise sincrônica em detrimento de uma diacrônica: a consequiência mais saliente, aqui, é a criação de uma imunidade da imagem e dos valores a ela associados em relação ao fator 
temporal. Em terceiro lugar, apesar das prevenções explicitadas em alguns trabalhos, ocorrem certos problemas com o estabelecimento do corpus documental: desde uma concentração em imagens individuais, em oposição a um trabaIho com séries (o que se verificou mais raro entre os artigos analisados) até um isolamento das imagens em suporte cerâmico do conjunto das imagens visuais (realmente, verificou-se um privilegiamento exagerado das ilustrações em vasos). Por fim, gostaria de lembrar que uma concentração desmedida de esforços na análise da imagem e seus significados pode encaminhar a pesquisa no sentido de eclipsar aspectos importantes da existênciá social das próprias imagens, que, por isso, mereceriam maior atenção. Cito apenas dois desses aspectos: de um lado, questões ligadas aos procedimentos pelos quais a sociedade estabelece as formas de representação plástica de suas experiências e realidades, ou seja, os mecanismos de figurabilidade, através dos quais um elemento, digamos a mulher, passa a ter existência icônica, além da existência biológica, social e psicológica; de outro lado, uma série de problemas que se relacionam com as condições de percepção da imagem na sociedade estudada, que não podiam deixar de ser lembrados, especialmente quando se trata a imagem como um sistema comunicativo de valores: são questões que teriam de tratar com os postulados de uma suposta invariância fisiológica e psíquica do ato de ver e também com os debates acerca da historicidade da percepção e sua mutabilidade cultural.

Todos esses problemas colocam a semiologia da imagem visual frente a problemas a serem pensados, mais cedo ou mais tarde. Se muito foi feito, até aqui, no sentido de superar uma postura que marginalizava a imagem no processo de produção do conhecimento histórico, as aquisições teóricas e metodológicas ainda são insuficientes para consagrar a abordagem semiológjca como o conjunto de instrumentos mais adequados e proveitosos à operação historiográfica. A inserção da imagem na história, que em grande parte deve ser creditada a esta corrente semiológica, deve corresponder uma inserção da história na imagem, com todas as conseqüências daí advindas para a análise iconográfica. Tarefa difícil e da qual depende o futuro das relações entre a imagem e a história. Resta saber se a semiologia é capaz de realizáta.

\section{BIBLIOGRAFIA}

D'AGOSTINI, B. L'immagine, la pittura e la tomba nell'Etruria arcaica. In: 1987 Bérard, C., Bron, C. e Pomari, A. (eds.). 1987: 213-220.

BARI, V.C. DI e ORSOLINI-RONZITTI, G.. L'elaborazione elettronica dei vasi 1983 attici a figure nere e rosse del "Corpus Vasorum Antiquorum". In: F. Lissarague e F. Thelamon (eds.). 1983: 81-90.

BAZANT, J.. Les vases athéniens et les réformes démocratiques. In:C. 1987 
BÉRARD, C.. Héros de tout poil. D'Héraklès imberbe à Tarzan barbu: Petite 1983a sémiologie d'Héraclès, In: F.Lissarrague e F. Thelamon (eds.). 1983: 111-119.

1983b Iconographie, iconologie, iconologique, Études de Lettres. Revue de la Faculté de Lettres, , Université de Lausanne (4).

1987 Etrangler un lion à mains nues: Nouvelles variations héracléennes. In: C. Bérard, C. Bron e A. Pomari (eds.). 1987: 177-186.

1992

Polythéisme éleusinien. In: Bron, C. e Kassapoglou, E. (eds.). 1992: 35-146.

BÉRARD, C., BRON, C. e POMARI, A. (eds.). Images et société en Grèce anci1987 enne. L'iconographie comme méthode d'analyse. Actes du Colloque International de Lausanne (8-11 de fevereiro de 1984). Lausanne (Cahiers d'archéologie Romande, 36).

BÉRARD, C. e DURAND, J-L. Entrer en imagerie. In: J.-P.Vernant. (pref.) 1984: 1984 19-34.

BRON, C. Porteurs de thyrse ou Bacchants. In: Bérard, C., Bron,C. e 1987 Pomari, A. (eds.), 1987: 145-153.

1992 La gent ailée d'Athéna Poliade. In: Bron,C. e Kassapoglou, E. (eds.), 1992: 47-84.

BRON, C. e KASSAPOGLOU, E. (eds.). L 'image en jeu. De l'Antiquité à Paul $1992 \quad K l e e$. Yens-sur-Morges, Institut d'Archéologie et d'Histoire Ancienne de l'Université de Lausanne/Editions Cabédita.

CALAME, C.. Quand regarder c'est énoncer: le Vase Pronomos et le masque. 1987 In: Bérard, C., Bron, C. e Pomari, A. (eds.). 1987: 79-88.

CARDOSO,Ciro F.S.. Iconografia e História. Resgate - Revista Interdisciplinar 1990 do Centro de Memória da UNICAMP, 1: 9-17.

CONSTANTINI, M.. Tekmessa: de l'herméneutique en iconographie. In: Bron, 1992 C. e Kassapoglou, E. (eds.). 1992: 85-102.

DUCREY, P.. Victoire et défaite: Réflexions sur la représentation des vaincus1987 dans l'art grec. In: Bérard, C., Bron, C. e Pomari, A. (eds.). 1987: 201-211.

DURAND, J.-L.. Le boeuf à la ficelle. In: Bérard, C. Bron, C. e Pomari, A. 1987 (eds.). 1987: 227-241. 

25-34.

DURAND,J-L. J. e LISSARRAGUE, F.. Héros cru ou hôte cuit: Histoire quasi 1987 cannibale d'Héraklès chez Busiris. In: Lissarrague, F. e Thelamon, F. (eds.). 1983: 153-167.

FRONTISI-DUCROUX, F. Face et profil: les deux masques. In: Bérard C., 1987 Bron, C. e Pomari, A. (eds.) 1987: 89-102

GLYNN, R.. The Beazley Archive Computer Project. In: Lissarrague, F. e The 1983 lamon, F. (eds.). 1983: 67-79.

JOYAN, F. Autour du sacrifice d'Iphigéne. In: Texte \& Image. 61-74. 1984

KAHIL, L.. Artémis en relation avec d'autres divinités à Athènes et en Attique. 1984 In: Texte E Image. 53-60.

LAGRANGE, M.-S. e RENAULD, M.. L'interprétation des documents figurés en 1983 Archéologie et Histoire de l'Art: Essai de simulation sur ordinateur. In: F. Lissarrague e F. Thelamon (eds.). 1983: 43-66.

LAURENS, A.F.. Identification d'Hébé: Le nom, l'un et le multiple. In: 1987 Bérard,C., Bron, C. e Pomari,A. (eds.). 1987: 59-72.

LISSARRAGUE, F.. Dionysos s'en va-t-en guerre. In: Bérard,C., Bron, C. e 1987 Pomari, A. (eds.). 1987: 111-120.

1991 Femmes au figuré. In: Perrot, M. e Duby,G. (orgs.) . Histoire des femmes en Occident. Vol. 1: L'Antiquité. Paris; Plon: 159-261.

1992

Graphein: écrire et dessiner. In: Bron, C. e Kassapoglou, E. (eds.). 1992: 189-203.

LISSARRAGUE, F. e THELAMON, F. (eds.). Image et céramique grecque. Ac1983 tes du Colloque de Rouen (25-26 de novembro de 1982). Rouen Publications de l'Université de Rouen, 96.

MANFRINI-ARAGNO, I.. Femmes à la fontaine: réalité et imaginaire. In: Bron, 1992 C. e Kassapoglou, E. (eds.). 1992: 127-148.

MIQUEL, C.. Images d'Hermès. In: Bron, C. e Kassapoglou, E.(eds.). 1983: 131983 23. 
NOEL, D.. Du vin pour Héraklès. In: Lissarrague, F. e Thelamon, F. (eds.). 1983 1983: 141-150.

POMARI, A.. Le massacre des innocents. In: Bron, C. e Kassapoglou, E. (eds.) 1992 1992: 103-125.

SCHEFOLD, K.. Texte et image à l'époque archaïque grecque. In: Texte \& 1984 Image: 41-52.

SCHIMITT-PANTEL, P. e THELAMON, F.. Image et Histoire: illustration ou do1983 cument. In: Lissarrague, F. e Thelamon, F. (eds.). 1983: 9-20.

SCHNAPP, A.. Héraclès, Thésée et les chasseurs: les ambigüités du héros. In: 1987 Bérard, C., Bron, C. e Pomari, A. (eds.). 1987: 121-130.

SIEBERT, G. (ed.) Méthodologie iconographique. Actes du Colloque de 1981 Strasbourg . Strasbourg, AECR.

SOURVINOU-INWOOD, C.. Menace and pursuit: differentiation and creation 1987 of meaning. In: Bérard, C., Bron, C. e Pomari, A. (eds.). 1987: 41-58.

TEXTE \& IMAGE. Actes du Colloque International de Chantilly (13-15 de ou1984 tubro de 1982). Paris, Les Belles Lettres.

TOUCHEFEU, O.. Lecture des images mythologiques. Un exemple d'images 1983 sans texte: la mort d'Astyanax. In: Lissarrague, F. e Thelamon, F. (eds.). 1983: 21-28.

VERBANCK-PIERARD, A.. Images et croyances en Grèce ancienne: représen1987 tations de l'apothéose d'Héraclès au VIè. Siècle". In: Bérard, C., Bron, C. e Pomari, A. (eds.). 1987: 187-199.

VERNANT, J.-P. (org.).. La cité des images. Religion et société dans la Grèce 1984 antique. Paris/Lausanne, Fernand Nathan/LEP.

VICKERS, M. Les vases peints:image ou mirage?. In: F.Lissarrague e 1983 F.Thelamon (eds.). 1983: 29-42.

1987

Dates, methods and icons. In: Bérard, C. Bron, C. e Pomari, A. (eds.). 1987: 19-25.

VILLANUEVA-PUIG, M.C.. Sur l'identité de la figure féminine assise sur un 1987 taureau dans la céramique attique à figures noires. In: Bérard, C., Bron, C. e Pomari, A. (eds.). 1987: 131-143. 
VILLARD, L.. Entre l'inventaire et la recherche: une tentative de compromis 1983 par l'informatique. In: Lissarrague, F. e Thelamon, F. (eds.). 1983: 91-102.

VIRET-BERNAL, F.. VALLOTON, F., ROGGER, A. e BRON, C.. D'Héraclès à 1992 Guillaume Tell. Portrait d'un héros. Application de T.I.R.E.S.I.A.S.. In: Bron, C. e Kassapoglou, E. (eds.). 1992: 173-188.

VOVELLE, M. (ed.). Iconographie et Histoire des Mentalités. Paris, CNRS. 1979.

WILLIAMS, D.. Herakles, Peisistratos and the Alcmeonids. In: Lissarrague, F. e 1983 Thelamon, F. (eds.). 1983: 121-140.

WOODFORD, S.. The iconography of the infant Herakles strangling snakes. 1983 In: Lissarrague, F. e Thelamon, F. (eds.). 1983: 121-130. 